\title{
Curiosity among School going Students
}

\author{
Dr. Shashi Kala Singh ${ }^{1}$
}

\section{ABSTRACT:}

Aim of the present research was to find out the curiosity among school going students as related to gender, socio-economic status and place of residence. Participants were 200 children (100 boys and 100 girls) from different schools of Ranchi town. The scale used was Children's Curiosity Scale developed by Kumar (1992). Data were analysis by F test. Result showed that there was no significant difference between boys and girls students on curiosity. There was significant difference between curiosities of high and low socio-economic status students. There was no significant difference between urban and rural students.

Keywords: Curiosity, gender, socio-economic status and place of residence

Curiosity is a concept which tells the desire to learn. Human beings think, judge, interrogate, argue and wants to learn. Many reasons can create curiosity in a person. Curiosity is an important human trait which has been credited with a great deal of the world's progress. Curiosity is a term that describes a number of behavioural and psychological mechanisms, which have the effect of impelling living beings to seek information and interaction with their environment and with other beings in their vicinity. When studies on this area are analysed researchers emphasize concepts which cause inquisitiveness like new, interesting, abnormal or mystic items, giving the positive input such as inquiry and direction, expressing willingness and desire to learn much more about environment. Curiosity is common to human being of all ages from infant to old age and is easy to observe in many other animal species. It has been found to be a significant factor in the learning process, the sign of a vigorous intellect and also important in problem solving and creative thinking. Curiosity drives the child to investigate and explore items of interest, to touch and handle, to walk away only to revisit it again. Curiosity is a state of increased arousal response, promoted by a stimulus high in uncertainty and lacking of information, external stimuli such as novelty, uncertainty, conflict and complexity create an internal state of arousal. Curiosity is defined as the intrinsic desire to know, to see, or to experience something, which motivates information seeking behavior (Zelick, 2007). Acquiring knowledge out of curiosity is considered to be intrinsically rewarding and highly pleasurable, since it eliminates states of ignorance and uncertainty (Litman, 2005). There are two main theoretical accounts of curiosity.

${ }^{1}$ Associate Professor, University Department of Psychology, Ranchi University, Ranchi (c) 2015 I S Singh; licensee IJIP. This is an Open Access Research distributed under the terms of the Creative Commons Attribution License (http://creativecommons.org/licenses/by/2.0), which permits unrestricted use, distribution, and reproduction in any Medium, provided the original work is properly cited. 


\section{Curiosity among School going Students}

These two accounts of curiosity may seem different and incompatible. In the context of this circumstance, another theoretical approach, the I/D model ("interest/deprivation" model), will be presented later on. This model that can reconcile these two seemingly incompatible views was suggested by Zelick (2007).

The first one is curiosity drive theory, which expresses the concept of curiosity as a drive state that arouses intrinsic motivation to seek information with the intention of reducing unpleasant feelings concerning uncertainty, in another word; it is curiosity reduction (Litman, 2005). The second one is optimal arousal theory, which states individuals who have intrinsic motivation to search for new information aim at maintaining and enhancing pleasurable feelings of interest. Organisms that are under-aroused are motivated to seek for new stimulation that can excite their curiosity.

\section{TYPES OF CURIOSITY}

- Diversive curiosity: - A general condition as that may be considered the need to seek new experiences or extend one's knowledge in to the unknown.

- Epistemic curiosity: - The desire to gain knowledge.

- Specific Curiosity: - The aroused state of an organism when confronted by an ambiguous stimulus that may result in specific exploration (Day 1968).

- State curiosity: - Individual differences in response to a particular curiosity - arousing situation.

- Trait curiosity: - Individual differences in the ability to experience curiosity.

\section{REVIEW OF LITERATURE}

Most of the investigators dealing with the relationship between gender and curiosity have observed similar sex differences with regard to curiosity. Kauser (1982) and Nandi (1988) found the boys generally having higher curiosity than girls. Gatto (1929) found that children differing in gender also differed in the areas in which they expressed their greatest curiosity. Coie (1974) made an attempt to evaluate the cross - situational stability of children's curiosity and examined their exploratory Behaviour across conditions of varying content and adult sanction to explore. Results indicate sex differences with regard to curiosity with boys being less timid about exploring without clear adult permission to do so. Smith (1957) pointed out that girls tended to be less curious than boys because of greater restrictions on their explorations. Kauser (1982) found significant difference in curiosity between the high and low socio-economic status students. Davis (1932) found the similar sex difference as other investigators and further reported that boys asked for more causal explanations while girls were more curious about social relationship.

\section{HYPOTHESES}

- There will be no significance of difference among boys and girls in terms of curiosity

- There will be no significance of difference among high and low socio economic group in terms of curiosity

- There will be no significance of difference among urban and rural students in terms of curiosity 


\section{METHOD}

\section{Sample}

Sample of the present study consisted of 200 students. 100 students were boys and 100 were girls. Each category was again divided into high and low socio-economic status (100 students from high socio-economic status \& 100 from low socio-economic status, 100 urban \& 100 rural). The samples were collected from students of class VI.

\section{Instrument}

Children's Curiosity Scale: - The scale was developed by Kumar (1992). It is a four point scale to study some attitude and habits of the children. The scale consists of 44 items. Brown formula for correction, a reliability coefficient of 0.87 was obtained.

\section{Variables under the study}

The present study was designed to find out the effect of independent variable and dependent variables. Following variables were studied:-

Independent variable:-

- Gender- Boys (A1) and Girls (A2)

- Socio-economic status- High (B1) and Low (B2)

- Place of Residence- Urban (C1) and Rural (C2)

Dependent variable:-

- Curiosity scale

\section{RESULT AND DISCUSSION}

Table $-1-$ The F value obtained for the variable of Curiosity.

\begin{tabular}{|l|l|l|l|l|}
\hline Sources of Variations & Sum of Squares & Mean Square & $\begin{array}{l}\text { Degree of } \\
\text { Freedom }\end{array}$ & F ratio \\
\hline Main effects & & & & \\
\hline A. Gender & 377.6267 & 7896.8762 & 1 & $0.45(\mathrm{NS})$ \\
\hline B. Socio-economic status & 7086.4067 & 20.6716 & 1 & $8.60 * *$ \\
\hline C. Place of Residence & 457.8267 & 197.7416 & 1 & $0.55(\mathrm{NS})$ \\
\hline $\begin{array}{l}2 \quad \text { way interaction } \\
\text { A X B }\end{array}$ & 708.4033 & 3892.97 & 1 & $0.86(\mathrm{NS})$ \\
\hline A X C & 5.3333 & 4017.51 & 1 & $0.006(\mathrm{NS})$ \\
\hline B X C interaction & 590.8033 & 220.93 & 1 & $0.72(\mathrm{NS})$ \\
\hline $\begin{array}{l}\text { A way B X C } \\
\text { A X }\end{array}$ & 869.6933 & 945.13 & 1 & $1.05(\mathrm{NS})$ \\
\hline Withintreatment & 118223.5267 & 403.04 & 142 & \\
\hline
\end{tabular}

**Significant at 0.01

NS:-Not Significant 
Table 2 - Difference between mean score of curiosity with reference to gender, socio-economic status and place of residence.

\begin{tabular}{|l|l|l|l|}
\hline Independent Variable & N & Mean & Difference between Mean \\
\hline Boys(A1) & 100 & 75.87 & 3.27 \\
\cline { 1 - 3 } Girls (A2) & 100 & 79.14 & (A1X A2) \\
\hline High (B1) & 100 & 81.36 & 13.75 \\
\cline { 1 - 2 } Low (B2) & 100 & 67.61 & (B1X B2) \\
\hline Urban(C1) & 100 & 75.54 & 3.5 \\
\cline { 1 - 2 } Rural (C2) & 100 & 79.04 & (C1 X C2) \\
\hline
\end{tabular}

Figure 1 - Mean of curiosity with reference to gender, socio economic status and place of residence



\section{Curiosity with reference to gender:-}

When $\mathrm{F}$ test was applied to check the impact of curiosity on gender, insignificant $\mathrm{F}$ value was found. The F value (Table-1) was 0.45 which are statistically not significant. Table -2 revealed that the mean score of curiosity of boys and girls students are 75.87 and 79.14 respectively and the difference between two groups was 3.27. Hence, the null hypothesis there will be no significance of difference among boys and girls in terms of curiosity was proved.

\section{Curiosity with reference to socio-economic status:-}

When $\mathrm{F}$ test was applied to check the impact of curiosity on socio-economic status, significant $\mathrm{F}$ value was found. The $\mathrm{F}$ value (Table-1) was 8.60 which were statistically significant at 0.01 level. Table -2 revealed that the mean score of curiosity of high and low socio-economic status student are 81.36 and 67.61 respectively and the difference between two groups was 13.75, which was very high. Hence, the null hypothesis there will be no significance of difference among high and low socio economic group in terms of curiosity was rejected. It was concluded that there was a significant impact of curiosity on high and low socio-economic status.

\section{Curiosity with reference to place of residence:-}

When $\mathrm{F}$ test was applied to check the impact of curiosity on place of residence, insignificant $\mathrm{F}$ value was found. The F value (Table-1) was 0.55 which are statistically not significant. Table -2 revealed that the mean score of curiosity of urban and rural students are 75.54 and 79.04 respectively and the difference between two groups was 3.5. Hence, the null hypothesis there will be no significance of difference among urban and rural students in terms of curiosity was accepted. 


\section{Curiosity among School going Students}

Curiosity with reference to interaction effects gender, socio-economic status and place of residence:-

All interaction effects were found statistically insignificant.

\section{CONCLUSION}

- There was no significant difference between boys and girls students on curiosity.

- There was significant difference between curiosity of high and low socioeconomic status students.

- There was no significant difference between urban and rural students.

\section{REFERENCES}

Coie, J. D. (1974). An evaluation of the cross-situational stability of children's curiosity. Journal of Personality, 42, 93-112.

Davis, E.A. (1932).The form and function of children's questions. Child Devlopment, 3, 57 74.

Gatto, F.M. (1929).Pupils questions: Their nature and their relationship to the study process. University of Pittsburgh Bulletin,26, $65-71$.

Kauser, F. (1982). Children's curiosity and its relationship to intelligence, curiosity and personality, Ph.D.Psychology, University of Madras. In M.B Buch (Ed.), Third survey of Research in Education (1978-83). New Delhi: National council of Educational Research and Training, 1986.

Litman, J. A. (2005). Curiosity and the pleasures of learning: Wanting and liking new information. Cognition and Emotion, 19 (6), 793-814.

Nandi, J. (1988). A study of curiosity of high school children in relation to sex and socio economic status. Proceedings of the $75^{\text {th }}$ session of the Indian Science Congress Association. Calcutta.

Smith, W. W. (1957). Remarriage and the step child. Development Psychology. New Delhi: Tata Mc Graw - Hill Publishing Co.214 - 215.

Zelick, P. R. (2007). Issues in the psychology of motivation. New York: Nova Science Publishers. 